\title{
Impact of urbanization on abundance and phenology of caterpillars and consequences for breeding in an insectivorous bird
}

\author{
Gábor Seress, ${ }^{1,6}$ Tamás Hammer,,${ }^{1}$ Veronika Bókony, ${ }^{2}$ Ernő Vincze, ${ }^{3}$ Bálint Preiszner, ${ }^{4}$ Ivett Pipoly, ${ }^{1}$ \\ Csenge Sinkovics, ${ }^{3}$ Karl L. Evans, ${ }^{5}$ And András Liker ${ }^{1,3}$ \\ ${ }^{1}$ Department of Limnology, University of Pannonia, Veszprém, Hungary \\ ${ }^{2}$ Lendület Evolutionary Ecology Research Group, Plant Protection Institute, Centre for Agricultural Research, Hungarian \\ Academy of Sciences, Budapest, Hungary \\ ${ }^{3}$ MTA-PE Evolutionary Ecology Research Group, University of Pannonia, Veszprém, Hungary \\ ${ }^{4}$ Balaton Limnological Institute, Centre for Ecological Research, Hungarian Academy of Sciences, Tihany, Hungary \\ ${ }^{5}$ Department of Animal and Plant Sciences, University of Sheffield, Sheffield S10 2TN, United Kingdom
}

\begin{abstract}
Urbanization can have marked effects on plant and animal populations' phenology, population size, predator-prey, interactions and reproductive success. These aspects are rarely studied simultaneously in a single system, and some are rarely investigated, e.g., how insect phenology responds to urban development. Here, we study a tri-trophic system of trees, phytophagous insects (caterpillars), and insectivorous birds (Great Tits) to assess how urbanization influences (1) the phenology of each component of this system, (2) insect abundance, and (3) avian reproductive success. We use data from two urban and two forest sites in Hungary, central Europe, collected over four consecutive years. Despite a trend of earlier leaf emergence in urban sites, there is no evidence for an earlier peak in caterpillar abundance. Thus, contrary to the frequently stated prediction in the literature, the earlier breeding of urban bird populations is not associated with an earlier peak in caterpillar availability. Despite this the seasonal dynamics of caterpillar biomass exhibited striking differences between habitat types with a single clear peak in forests, and several much smaller peaks in urban sites. Caterpillar biomass was higher in forests than urban areas across the entire sampling period, and between 8.5 and 24 times higher during the first brood's chick-rearing period. This higher biomass was not associated with taller trees in forest sites, or with tree species identity, and occurred despite most of our focal trees being native to the study area. Urban Great Tits laid smaller clutches, experienced more frequent nestling mortality from starvation, reared fewer offspring to fledging age, and their fledglings had lower body mass. Our study strongly indicates that food limitation is responsible for lower avian reproductive success in cities, which is driven by reduced availability of the preferred nestling diet, i.e., caterpillars, rather than phenological shifts in the timing of peak food availability.
\end{abstract}

Key words: arthropod; breeding phenology; caterpillar biomass; food limitation hypothesis; frass; nestling food; nestling mortality; trophic mismatch; urban birds.

\section{INTRODUCTION}

Urban animal populations often differ from populations living in natural habitats in their life history, demography, and reproductive success (Sepp et al. 2017). Several bird species lay earlier in urban areas, and it is hypothesized that in species that primarily feed their offspring with phytophagous insects earlier breeding is an adaptation to the earlier seasonal peaks in food availability in response to urban heat island effects (Vaugoyeau et al. 2016). Although birds' reproductive success may be either increased, decreased, or not affected by urban development, this depends on the species' characteristics (Marzluff et al. 2016, Tomasevic and Marzluff 2017, Kettel et al. 2018), with urban populations of insectivorous birds tending to have smaller clutches, and to produce fewer fledglings that have lower body mass compared to rural populations (Chamberlain et al. 2009, Seress et al. 2012). These differences in reproductive success may be driven by changes in a range of

Manuscript received 24 July 2017; accepted 10 April 2018. Corresponding Editor: John M. Marzluff.

K.L. Evans and A. Liker are joint last authors of this study.

${ }^{6}$ E-mail: seressg@almos.uni-pannon.hu environmental conditions, including temperature, food availability, nest predation, air pollution, and light pollution, but the precise nature of the mechanisms involved remain unclear (Gil and Brumm 2014). The decreased quantity and quality of green space in cities may reduce the abundance of phytophagous arthropods (New 2015), which are the primary source of nestling and adult food in many bird species, and this may consequently lead to decreased avian reproductive success in urban environments as proposed by the foodlimitation hypothesis. Reduced availability of these preferred food items may result in smaller clutch sizes due to food limitation of egg-laying females, and also reduce nestling growth and survival (Chamberlain et al. 2009, Seress and Liker 2015). For cavity-nesting birds, natural food availability is likely to be a particularly important determinant of breeding success because they experience relatively low nest predation rates in natural (Martin 1995) and also in urbanized areas (Tomasevic and Marzluff 2017, Vincze et al. 2017), hence are less sensitive to variation in nest predation risk along the urban-rural gradient than species with more open nests.

So far, few studies have simultaneously investigated natural food availability (i.e., abundance of specific prey items) and breeding success of urban insectivorous birds, and in 
general, their results suggest a link between the scarcity of arthropods and decreased breeding success in birds. For example, the availability of arthropod prey for Florida Scrub-jays Aphelocoma coerulescens was 50\% lower in suburbs than in natural scrub habitats, with a higher rate of brood reduction in suburbs (Shawkey et al. 2004), and similarly, suburban House Sparrows had lower breeding success and provided fewer large arthropod prey items to their nestlings compared to rural conspecifics (Seress et al. 2012). Great Tits (Parus major) and Blue Tits (Cyanistes caeruleus) primarily feed their nestlings caterpillars (lepidopteran larvae, mainly moths) collected in tree canopies (Perrins 1991), and have been well studied in urban sites, where they often have reduced reproductive success (Solonen 2001, Marciniak et al. 2007, Glądalski et al. 2015, Wawrzyniak et al. 2015, Bailly et al. 2016). Some of these studies also investigated caterpillar availability but reported lower, higher or similar caterpillar abundance in urban habitats relative to natural breeding sites (see Table S1 for details). The population sizes of other arthropod taxa also exhibit heterogeneous responses to urbanization (McIntyre 2000, Raupp et al. 2010, Jones and Leather 2012, New 2015, Leong et al. 2016). There is thus insufficient understanding of how urbanization influences the availability of natural prey for insectivorous birds.

Phenology is a key factor influencing the availability of lepidopteran larvae for nestlings (Perrins 1991, Verboven et al. 2001), and this seasonality may also be influenced by urbanization. The urban heat island effect can significantly advance vegetation phenology (Neil and Wu 2006) and the onset of reproductive cycles in many arthropods including phytophagous species (Forrest 2016). In contrast, the appearance of 28 European butterfly species in human settlements is 9-10 d later than in forests and agricultural areas (Altermatt 2012), and urbanization is associated with phenological delays in first and peak appearance dates of several North American butterfly species (Diamond et al. 2014). The dates of arboreal caterpillar biomass peaks, however, did not differ consistently between an urban parkland area and a woodland habitat in central Poland (Wawrzyniak et al. 2015; see Appendix S1: Table S1). Thus, understanding how and to what extent urbanization influences arthropod prey phenology and abundance is far from sufficient, even though such changes could have severe impacts on urban birds' breeding success. To maximize reproductive success, birds often time their breeding to synchronize nestlings' maximal food demand with the maximal food availability (Van Noordwijk et al. 1995, Hegyi et al. 2013). Thus, if the timing of the peak abundance of nestling food is changed in urban environments, this may lead to a mismatch between the nestling period and the peak of arthropod food if the birds are not able to adjust their timing of breeding as well. Therefore, changes in the seasonal pattern of arthropod abundances will influence the timing of peak food availability and may thus influence the optimal timing and success of avian breeding attempts.

In this study, our primary objective is to integrate data on leaf emergence, caterpillar biomass and phenology, and avian breeding success into a single comprehensive study assessing how urbanization influences the phenology of a multi-trophic system, caterpillar abundance and the resultant consequences for avian breeding success. To do so, we intensively and regularly sampled caterpillar abundance during the avian breeding cycle and replicated our study over four years, with contrasting meteorological conditions, using two urban and two forest study sites. This provides a robust comparison of caterpillar biomass and its seasonal dynamics between urbanized and natural habitat types, based on spatially and temporally more extensive sampling than most of the earlier studies (Appendix S1: Table S1). Based on the findings of earlier studies discussed above, we test four hypotheses: (1) trees' leaf emergence date is advanced in urban areas; (2) urban and forest caterpillar populations exhibit divergent phenological patterns; (3) urban Great Tits breed earlier than their forest conspecifics; and (4) the food limitation hypothesis, i.e., that reduced caterpillar biomass in urban areas compared to forests contributes to lower avian reproductive success. In meeting these core objectives, we also assess if tree height and tree species identity contribute to differences in caterpillar biomass between urban and forest habitats.

\section{Methods}

\section{Study sites and years}

We conducted our study from 2013 to 2016 in Hungary, in two forest and two urban sites (Appendix S1: Fig. S1). Forest sites represented a mixed beech Fagus sylvatica and hornbeam Carpinus betulus forest (Szentgál) and a mixed downy oak Quercus cerris and South European flowering ash Fraxinus ornus forest (Vilma-puszta); these are two common types of forests in Hungary (Borhidi 2003). The two forest sites are mature woodlands located $2-3 \mathrm{~km}$ away from the nearest human habitation. Urban sites (Veszprém and Balatonfüred) are within typical Hungarian towns and included public parks, a cemetery, a bus station, and university campuses within a landscape dominated by buildings and impervious surfaces.

Weather conditions differed markedly between years. In 2013, the pre-breeding season was colder than usual with snow cover in early April (Appendix S1: Fig. S2). Conversely, the pre-breeding season was unusually warm in 2014 but, in 2015 and 2016, was more typical for the study area (Appendix S1: Fig. S2). From April to June, the mean monthly temperatures were similar in the four study years, and close to recent long-term means (Appendix S1: Fig. S2).

\section{Selected tree species}

We identified the most common tree species at each study site (by field survey conducted in 2013) and used these species for phenological monitoring of leaf emergence and caterpillar biomass. By sampling common tree species within each of the four study sites (Appendix S1: Table S2), we assessed differences in caterpillar abundance and phenology between urban and rural habitats as experienced by the birds. There was little similarity in the composition of tree assemblages across the four sites (indeed the composition of urban and rural tree communities is typically highly divergent, e.g., Dunn and Heneghan 2011) and the selected tree species therefore varied across sites. We used the two most 
common tree species at each of our forest sites (except the first study year, 2013, in which we used only the single most common species in Vilma-puszta). Urban areas contained more tree species so we selected the three commonest species at our two urban sites. All the selected tree species are native to Hungary except horse chestnut Aesculus hippocastanum, which was introduced several hundred years ago. All species, including horse chestnut, are frequently used by foraging tits during the breeding season (our personal observations; Grabenweger et al. 2005).

\section{Tree phenology}

We monitored leaf emergence phenology between February and April in 2014, 2015, and 2016 using 10 trees per species at each site. One of us (T. Hammer) visited them regularly with 2-7 d intervals, with shorter intervals closer to the timing of leaf emergence. For each tree we calculated the leaf emergence date as the date when $>50 \%$ of buds had emerged such that the leaves' shape was clearly recognizable but they were not yet fully grown (for a similar approach see Vitasse 2013).

\section{Frass sample collection and processing}

We followed the common approach of using frass (insect droppings) biomass as an index of caterpillar biomass (Tinbergen and Dietz 1994). We collected frass from 6 to 10 (2013) or 6 (2014-2016) mature individuals per tree species in each study site (Appendix S1: Table S2); all trees used for frass collection were used to monitor leaf emergence. We monitored the same individual trees throughout the study except that we changed one maple Acer platanoides tree in Veszprém due to logistical reasons. One of us (T. Hammer) estimated canopy height of trees from which frass was collected to the nearest $1 \mathrm{~m}$ by eye (after initial training and with the aid of a 3-m measuring stick placed against the tree trunk as a reference). Note that the estimated tree heights in our study had a wide range (8-25 m, interquartile range: $12-18 \mathrm{~m}$ ), and canopy height is typically highly correlated with canopy volume (Troxel et al. 2013).

We conducted frass sampling between March and June, i.e., covering the Great Tits' entire breeding season at each site, following standard protocols (Tinbergen and Dietz 1994, Glądalski et al. 2015). To collect frass, we used frassfall traps (cheese cloth net attached to a $0.5 \times 0.5 \mathrm{~m}$ wooden frame) suspended under the sampled trees' canopy (always below the lowest branch of the canopy in a position to avoid overlapping canopies of adjacent trees). Consequently, the amount of vegetation above the frass traps is determined by tree height. We used one frass trap per tree and emptied traps once every $3-5 \mathrm{~d}$ (mean $\pm \mathrm{SD}$ : $3.69 \pm 1.72$ ). We stored frass samples at room temperature, separated frass from non-frass particles, measured frass mass, and converted it to hourly caterpillar biomass $(\mathrm{mg} / \mathrm{h})$ following Tinbergen and Dietz (1994). We collected and measured a total of $1,084,1,271,1,246$, and 1,204 frass samples in 2013, 2014, 2015, and 2016, respectively. For more details on frass sample collection and processing and calculation of caterpillar biomass, see Appendix S2.

\section{Breeding phenology and success of Great Tits}

We monitored Great Tits breeding in nest boxes at least once every 3-4 d (twice per week) from 1 March until the end of June, when birds finished breeding at each study site. We recorded the laying date of the first egg and the number of eggs and chicks at each nest check. When we found more than one egg during a nest check, we back-calculated the first egg date by assuming that one egg was laid per day. The smallest observed clutch size was four, ensuring that we could calculate first egg dates to within one day of accuracy. We ringed and weighed nestlings just prior to fledging, i.e., when they were 14-16 d old (taking the day of hatching as day 1 ; mean $\pm \mathrm{SE}$; urban sites, $15.15 \pm 0.02 \mathrm{~d}$; forest sites, $15.09 \pm 0.02 \mathrm{~d}$ ). We captured and individually marked parents during brood rearing using one metal and three plastic color rings (Seress et al. 2017). We only analyzed data from first clutches, to provide results comparable to other studies of reproductive phenology and success of urban Great Tits (Solonen 2001, Wawrzyniak et al. 2015, Bailly et al. 2016). We regarded a clutch as the first breeding attempt of a pair if it was initiated before the date of the first egg laid in the earliest second clutch at that site by an individually identifiable (i.e., color-ringed) female that successfully raised her first clutch (i.e., fledged at least one young) in that year. Replacement clutches (i.e., clutches laid after failure of the first breeding attempt) were rare and excluded from the analyses. In this study, first breeding attempts produced the majority of fledglings in both habitat types in all years (2013, $82 \%$ and $66 \% ; 2014,75 \%$ and $77 \% ; 2015,92 \%$ and $96 \% ; 2016,71 \%$ and $77 \%$ in urban and forest habitats, respectively). We monitored a total of 63 (36 urban, 27 forest), 120 (51 urban, 69 forest), 122 (60 urban, 62 forest), and 112 (63 urban, 49 forest) first clutches in the four study sites in 2013, 2014, 2015, and 2016, respectively (see Appendix S1: Table S3 for more details).

\section{Statistical analyses}

We analysed the data from each study year separately (unless stated otherwise), and we report means with standard errors. We checked the validity of statistical assumptions for each linear model by inspecting residual plots for linearity, normality, and homoscedasticity (Zuur et al. 2009), and by calculating the variance inflation factor (VIF) where relevant (i.e., in models with more than one continuous explanatory variable) to assess multi-collinearity. Following Whittingham et al. (2006), we report the results of full models throughout (i.e., without model selection), except in two specific analyses. We define the statistical significance level at 0.05 and refer to results where $0.05<P<0.1$ as "marginally non-significant." All analyses were conducted in $\mathrm{R}$ v3.3.1 (R Core Team 2016).

Tree phenology. - To test for habitat differences in tree phenology, we used a linear mixed model (LME, package nlme) in which leaf emergence date of individual trees (expressed as the number of days elapsed from 1 January) was the response variable, habitat type was the predictor (urban vs. forest), and tree species was included as random factor. We do not report the results from models that include study site 
as an additional random factor because preliminary analyses demonstrated that doing so did not improve the models' fit (as assessed by likelihood ratio tests).

Caterpillar phenology.-We used three approaches to describe seasonal changes in caterpillar biomass $(\mathrm{mg} / \mathrm{h})$, transformed as $\log _{10}(x+0.0001)$ before the analyses. First, we fitted LME models separately for each site and year because seasonal changes in caterpillar biomass varied across the four years, and in some years also differed between study sites of the same habitat type. In these models, we used caterpillar biomass as the response variable, including data from all trees in each site, and treated each sample as a data point. Sampling date (number of days since 1 January) was included as a predictor, and tree species and individual tree identity (i.e., tree ID) were included as nested random factors. To model non-linear seasonal changes (i.e., to allow for a peak), we compared this linear model to a model that also included the quadratic term of date, and to a model that also included the quadratic and cubic terms of date. For each site in each year, we selected the best model based on the results of likelihood ratio tests; i.e., we chose the model that had significantly better fit than the rest if the test showed significant difference in model fit, while we selected the simplest model if the fits of models were not significantly different (Zuur et al. 2009). Second, we fitted models for each site and year using the cardidate $\mathrm{R}$ package (Rolinski et al. 2015). This package fits curves to environmental time series using Weibull-functions, and compared to the linear model approach has the advantage of being able to identify seasonal trends with multiple peaks (see Rolinski et al. [2007] for details of the method). We used the peakwindow function (with default settings) that applies a heuristic peak detection algorithm to identify separate peaks within a single season. In this analysis, the response variable was the mean caterpillar biomass across all trees for each sampling date (separately for each site). Finally, we compared peak caterpillar biomass dates of individual trees (i.e., the date when the estimated caterpillar biomass was maximal for a given tree) between habitats using LME models in which peak date (using a single data point from each individual tree) was the response variable and included habitat type as a predictor and site and tree species as nested random factors. Since variance in peak dates differed strongly between habitats (see Results) we used LME models that allow heterogeneous variances (varIdent function of the nlme package).

Caterpillar biomass. - To compare the quantity of caterpillar biomass between habitats, we built LME models of caterpillar biomass $(\mathrm{mg} / \mathrm{h})$, with habitat type as a predictor; random factors were tree species nested in study site and, when multiple samples from the same trees were analysed, the ID of individual trees nested within tree species. First, we used this model structure to test for habitat differences in caterpillar biomass estimated during the whole sampling period (March-June), treating the biomass estimate from each frass sample as an individual data point (hence tree ID was included as random factor in the model). Second, we tested the habitat difference in caterpillar biomass measured during the brood-rearing period of the first broods. This analysis was similar to the preceding one except that we used only the frass samples collected during the brood-rearing period (defined for each site and year as from the hatching date of the first brood until the date at which the last of the first broods was $14 \mathrm{~d}$ old). Finally, we tested for habitat differences in the maximum caterpillar biomass of individual trees (thus tree ID was not included as random factor).

Effects of tree characteristics on caterpillar biomass. - Additionally, we tested whether caterpillar biomass $(\mathrm{mg} / \mathrm{h})$ was related to two characteristics of the sampled trees: tree species and canopy height. We used LME models in which caterpillar biomass was the response variable (using all data, i.e., each sample of each individual tree), the species and canopy height of sampled trees were the predictors, and site and tree ID were included as nested random factors. Pairwise comparisons between tree species were conducted by Tukey post-hoc tests (using glht function of the multcomp $\mathrm{R}$ package). Finally, we also compared canopy height of our focal trees between habitats by using LME models that contained canopy height $(\mathrm{m})$ as the response variable, habitat type as predictor, and study site and tree species as nested random factors; one model was run for the 58 trees used in 2013 and one model for the 60 trees that were used in 2014-2016 (Appendix S1: Table S2).

Breeding phenology and breeding success of Great Tits. - The timing of breeding (laying date of the first egg), clutch size, number of fledglings and fledgling body mass were analysed using LME models with study site as a random factor in each model. For the laying date analysis, the response variable was date (i.e., the number of days elapsed from 1st of January until the laying of the first egg for each clutch), and the model contained habitat type as a predictor. In the clutch size analysis, the response variable was the maximum number of eggs recorded for each clutch, predictors were habitat type and laying date, and we excluded nests that were deserted during egg laying ( $n=11$ clutches).

To investigate breeding success, first we compared the proportion of successful and failed nests (defined respectively as fledging at least one young and producing no fledglings) between urban and forest habitats using a $\chi^{2}$ test. In this analysis, we included all nests with at least one laid egg and excluded cases when complete clutch or brood loss may have occurred due to the monitoring process $(n=7$; e.g., when a nest box fell or when chick mortality occurred soon after capturing a parent on the nest). Second, we compared the number of fledglings between habitats by LME models in which the response variable was the number of chicks alive when the brood was ringed (i.e., a few days before fledging), and predictors were habitat type and laying date. In this analysis we used only hatched nests, i.e., those in which at least one nestling hatched and we excluded nests in which nestling mortality may have occurred due to the monitoring process ( $n=5$ broods). Finally, we analysed fledgling body mass (at ringing age) as the response variable; the predictors were habitat type, hatching date, number of fledglings at ringing, fledgling age at ringing, and brood ID nested within site (as random factors).

To model potential differences in seasonal effects on breeding success in urban and forest populations, we added 
a habitat $\times$ laying date interaction to the above models of clutch size, number of fledglings, and fledgling body mass. When the interaction term was not significant, the majority of cases, we only present the results of models that exclude the interaction term to aid interpretation of the main effects.

The food limitation hypothesis predicts greater frequency of nestling starvation in urban areas. We thus carefully examined all cases of nestling mortality in our dataset and identified broods in which chicks probably died from starvation as those in which brood size decreased during the brood rearing period, and there was no evidence of (1) nest predation (evidenced by predator marks on chicks or damage to the nest box or nest structure), (2) nest desertion (death, but not the disappearance, of the entire brood between two consecutive nest checks), or (3) direct mortality effect of the monitoring procedure or adverse weather effects (e.g., the nest box fell from the tree or the nest was waterlogged); 32 broods experienced these conditions. Thus, we had 360 broods and 3,316 nestlings, from which only a very small number of broods $(5.5 \%)$ and nestlings (1.7\%) exhibited signs of disease (e.g., pox lesions, diarrhea) or had heavy ectoparasite loads. These parasitized or diseased nestlings were not more likely to occur in broods in which we recorded starvation-related mortality ( 7 out of 96 broods) than in broods that did not experience starvation-related mortality (13 out of 264 broods; $\chi^{2}$ test, $\chi^{2}{ }_{1}=0.752$, $P=0.386$ ). For this reason, and also because disease and parasites could interact with starvation by strengthening the effect of each other, we did not exclude these broods from the starvation-related mortality analyses.

Starvation-related nestling mortality was a rare event $(96$ out of 360 broods), so its robust analysis using a binary logistic framework would have required the use of penalized likelihood estimates or similar methods; such models cannot accommodate the random effects structure of our data. Furthermore, logistic models of our mortality data would suffer from over-dispersion and poor fit. Thus, we categorized broods into two groups, with and without starvation-related mortality, and compared the frequency of nests in which starvation-related mortality occurred between urban and forest habitats using Fisher's exact test. To assess the validity of our assumption that mortality was indeed related to starvation in these broods, we performed two additional analyses to confirm that mortality attributed to starvation was associated with smaller body size. First, using LME models we tested whether broods' mean body mass at ringing was lower in broods that experienced mortality before ringing compared to nests that did not; predictors were habitat type, laying date, fledgling age at ringing, and year and we applied site as random factor. Second, in some cases, we found chicks that died in the nest after ringing $(n=87$ chicks; predation events excluded), and we compared their body mass (measured at ringing) to those that successfully fledged from the nest; predictors were habitat type, laying date, and year and we applied brood ID nested in site as a random factor. Both of these analyses supported our classification of starvation-related mortality. First, at the brood level, mean nestling body mass at ringing was lower in broods in which mortality attributed to starvation occurred before ringing (Appendix S1: Table S4a). Second, nestlings that died between ringing and fledging (i.e., were found dead in the nest after ringing and their deaths could not be attributed to predation or other causes unrelated to starvation) also had lower body mass at ringing than their siblings that successfully fledged, suggesting that starvation at the individual level predicted mortality (Appendix S1: Table S4b).

\section{RESUlts}

\section{Tree phenology}

Urban trees had earlier leaf emergence than forest trees (mean differences \pm SE; 2014, $8.9 \pm 3.4 \mathrm{~d} ; 2015$, $5.5 \pm 2.7$ d; 2016, $5.7 \pm 3.3$ d; Fig. 1a). These differences were statistically significant in 2014 (LME, $F_{1,8}=6.73, P=$ $0.032)$, marginally non-significant in $2015\left(F_{1,8}=3.99\right.$, $P=0.081)$, and not significant in $2016\left(F_{1,8}=3.02\right.$, $P=0.121)$.

\section{Caterpillar phenology}

Quadratic or cubic models of caterpillar biomass provided a better fit to the data than models that only included a linear term for all sites and years (Appendix S1: Table S5), indicating that caterpillar biomass changes nonlinearly during the birds' reproductive season. Fitted models (Fig. 2) indicated that forest sites typically exhibited more marked seasonal variation in caterpillar abundance, with the greatest difference in caterpillar biomass between forests and urban sites occurring during the seasonal peak in biomass. This pattern was less clear in 2013, i.e., the year with a cold early spring.

Models fitted by Weibull functions suggested similar habitat differences in the seasonal dynamics of caterpillar biomass (Appendix S1: Fig. S3). This method almost invariably detected a single large seasonal peak in caterpillar biomass for the two forest sites vs. three to five small peaks dispersed over the sampling periods for the urban sites. In 2016, two sites departed from this pattern. Only a single peak was detected at one of our urban sites (Balatonfüred), which may be related to the consistently very low caterpillar biomass over the whole sampling period at this site in this year (Appendix S1: Fig. S3h). In the same year, two consecutive peaks were detected for one of the forest study sites (Szentgál, Appendix S1: Fig. S3j); the dip in biomass between these peaks occurred in a period with frequent and particularly heavy rainfalls that interrupted sample collection and may also have temporarily washed caterpillars from the focal trees, reducing the effectiveness of our sampling method.

The date of peak caterpillar biomass did not differ consistently between urban and forest habitats. First, we determined a single date of peak caterpillar biomass for each site and year combination as the date with the highest mean caterpillar biomass (Table 1). Although the low number of these site-level peak date estimates does not permit statistical comparison, Table 1 shows that one of our urban sites (Balatonfüred) was earlier, whereas the other (Veszprém) was later than at least one of the forest sites in three out of four years. In addition, the date of peak caterpillar biomass of individual trees did not differ between habitats (LME; 2013, $F_{1,2}=4.52, P=0.167 ; 2014, F_{1,2}=0.256, P=0.663$; 

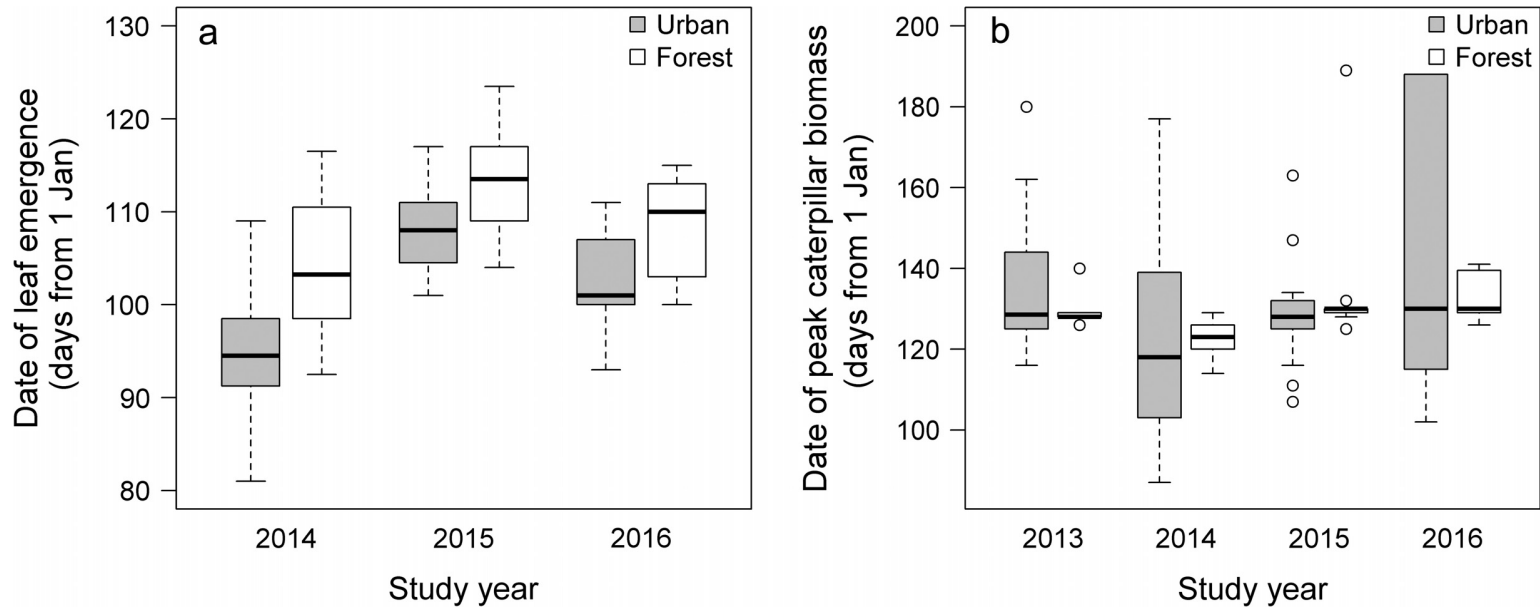

FIG. 1. (a) Differences in leaf emergence dates (measured as the date when $>50 \%$ of the sampled leaves were fully unfolded on a tree) and (b) variation in the date of maximum caterpillar biomass between urban (gray) and forest (white) trees in the study years. Medians and interquartile ranges are indicated by thick middle lines and boxes, respectively, while the whiskers represent maximum and minimum values and the open circles refer to the outliers.

2015, $F_{1,2}=0.69, P=0.492 ; 2016, F_{1,2}=0.11, P=0.772$; Fig. 1b). The variance in peak dates of individual trees was significantly higher in urban habitats than in forests in 2013, 2014, and 2016 (Levene's test; 2013, $F_{1,55}=9.96, P=0.002$; 2014, $\quad F_{1,58}=21.62, \quad P<0.001 ; \quad 2016, \quad F_{1,58}=21.64$, $P<0.001)$, but there was no difference in 2015 $\left(F_{1,58}=1.13, P=0.292\right.$; Fig. $\left.1 \mathrm{~b}\right)$.

\section{Caterpillar biomass}

Caterpillar biomass during the whole sampling period was significantly higher in forests than in urban habitats in all four years (Table $2 \mathrm{a}$ ): the difference was $\sim 12.5$-fold in 2013, 2.6-fold in 2014, 9.5-fold in 2015, and 11-fold in 2016 (Fig. 3a). We detected similar or even higher habitat differences in caterpillar biomass in each year when the comparison was restricted to the brood-rearing period of first broods (2013, 10.5-fold; 2014, 8.5-fold; 2015, 11-fold; 2016, 24-fold; Table 2b, Fig 3b) and when we compared the maximum caterpillar biomasses of individual trees (Table 2c, Appendix S1: Fig. S4).

\section{Effects of tree characteristics on caterpillar biomass}

We found that caterpillar biomass differed significantly between tree species in all years (Appendix S1: Fig. S5; LME; 2013, $F_{8,40}=12.94, P<0.001 ; 2014, F_{9,46}=5.40$, $P<0.001 ; \quad 2015, \quad F_{9,46}=12.63, \quad P<0.001 ; \quad 2016$, $\left.F_{9,46}=19.83, P<0.001\right)$. Pairwise post-hoc comparisons showed that urban tree species had significantly lower caterpillar biomass than forest species in 17 out of 18 comparisons in 2013, in 9 out of 24 comparisons in 2014, in 22 out of 24 comparisons in 2015, and in all of the 24 comparisons in 2016, whereas only five out of 77 comparisons between tree species within the same habitat type were significant (Appendix S1: Fig. S5, Table S6). This means that the higher urban caterpillar biomass was not restricted to specific tree species pairs (e.g., in 2016 all four forest tree species had higher caterpillar biomass than all six urban tree species).
Moreover, the comparisons of two oak (Quercus) species between urban and forest habitats showed higher caterpillar biomass at forest sites in all except one year (Appendix S1: Fig. S5, Table S6).

Canopy height had a significant positive effect on caterpillar biomass in 2013 (LME, $\left.F_{1,40}=8.90, P=0.005\right)$ and $2016\left(F_{1,46}=5.71, P=0.021\right)$, but not in $2014\left(F_{1,46}=1.69\right.$, $P=0.199)$ and $2015\left(F_{1,46}=1.04, P=0.313\right)$. Canopy height of the sampled tree individuals did not differ significantly between urban and forest habitats (LME; 2013, $\left.F_{1,2}<0.01, P=0.995 ; 2014-2016, F_{1,2}=0.01, P=0.931\right)$. As all frass traps were placed below the canopy of each tree, this result suggests that differences in the amount of frass collected in urban and forest sites are not simply a function of sampling taller trees, which have more foliage, at forest sites.

\section{Breeding phenology and breeding success of Great Tits}

Great Tits started to lay on average 6-7 d earlier in urban sites than in forests. This difference was significant in 2013 and 2016, non-significant in 2015, and was only $2 \mathrm{~d}$ and also statistically non-significant in the unusually warm spring of 2014 (Table 3a, Fig. 4a; Appendix S1: Table S3). Urban pairs had significantly smaller clutches than forest pairs in all years (Table 3b, Fig. 4b, Appendix S1: Table S3; 2013, by 3 eggs; 2014, by 1.2 eggs; 2015, by 3.4 eggs; 2016, by 3.6 eggs). In 2014, 2015, and 2016, there was a seasonal decline in clutch size of first broods in both habitat types, while we detected no such effect in 2013 (Table 3b; Appendix S1: Table S3).

Complete nest failure was rare $(n=37$ out of the 398 nests in the four years) but was significantly more frequent in urban ( $n=26$ out of the 196 nests, 13.3\%) than in forest ( $n=11$ out of the 202 nests, $5.4 \%$ ) habitats $\left(\chi_{1}^{2}=7.214\right.$, $P<0.007)$. Among pairs that hatched at least one chick, urban pairs fledged significantly fewer offspring per breeding attempt than forest pairs in 2013, 2015, and 2016 (mean difference of 4.8, 5.4, and 5.0 fledglings, respectively), while 


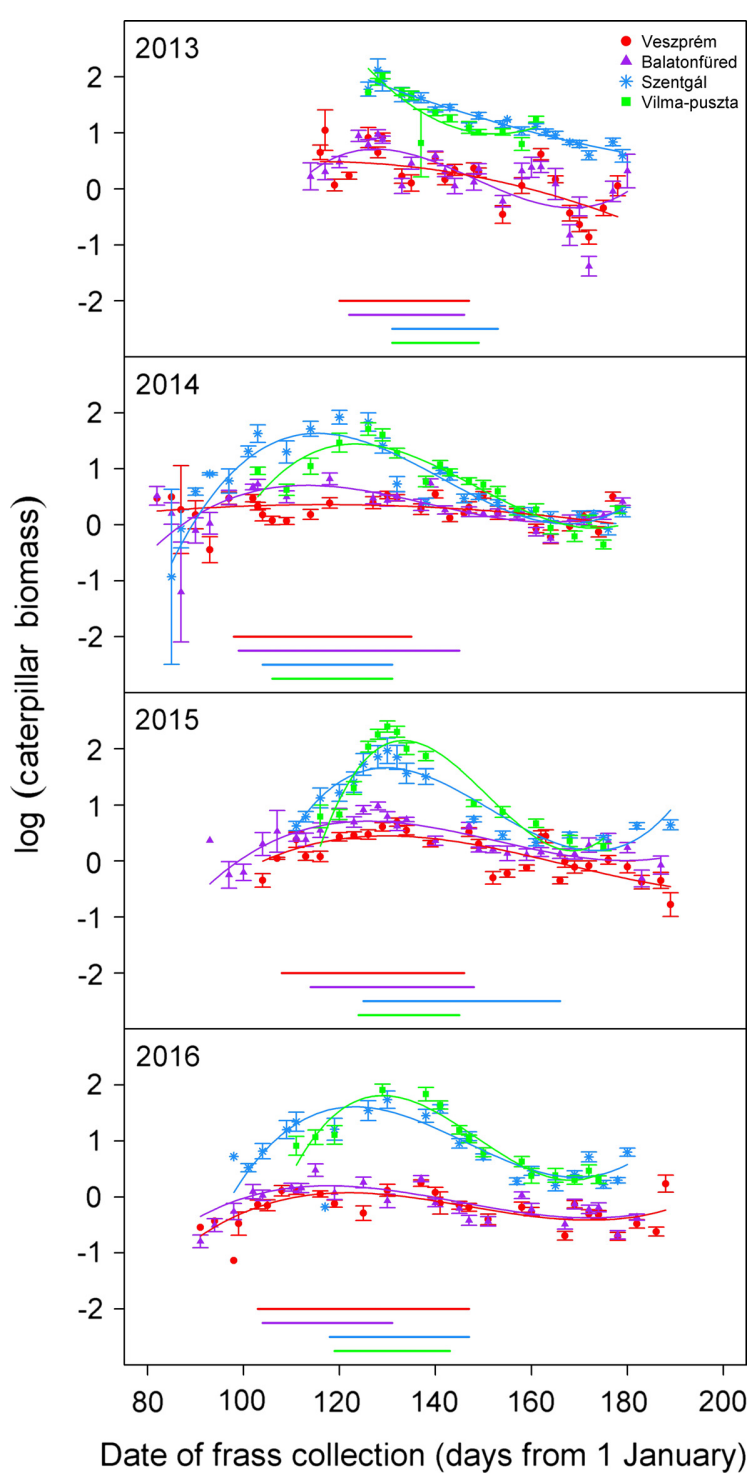

FIG. 2. Seasonal changes in caterpillar biomass $(\mathrm{mg} / \mathrm{h})$ over the whole sampling period in the urban sites (Veszprém and Balatonfüred) and forest sites (Szentgál and Vilma-puszta) in the four years. Dots and whiskers show the mean $\pm \mathrm{SE}$ of daily caterpillar biomasses for illustrative purpose only, because the models were fitted using all samples (see Statistical analyses: Caterpillar phenology and Appendix S1: Table S5 for details). The best fitting models are indicated by the curves fitted on the data. The horizontal lines at the bottom of the panels show the Great Tit brood-rearing period (for first broods) for each study site

TABle 1. Peak dates of caterpillar biomass in urban and forest habitats in the four study years

\begin{tabular}{lcccc}
\hline \hline & \multicolumn{4}{c}{ Date of maximum daily mean biomass } \\
\cline { 2 - 5 } Site & 2013 & 2014 & 2015 & 2016 \\
\hline Veszprém (urban) & 117 & 140 & 132 & 188 \\
Balatonfüred (urban) & 128 & 118 & 128 & 115 \\
Szentgál (forest) & 128 & 120 & 132 & 130 \\
Vilma-puszta (forest) & 129 & 126 & 130 & 138 \\
\hline
\end{tabular}

Notes: Within each site, peak date was estimated as the date with the highest mean caterpillar biomass (calculated across all trees). Dates are given as number of days since 1 January. in 2014 the difference between urban and forest habitats was much smaller (1.4 fledglings) and marginally non-significant (Table 3c, Fig. 4c; Appendix S1: Table S3). Earlier broods produced more fledglings than later broods in 2015 but not in other years (Table 3c).

Fledglings' body mass was significantly lower in urban broods than in forests in 2013, 2015, and 2016 (by 3.2, 3.4, and $3.3 \mathrm{~g}$ per chick, respectively), whereas the habitat difference was smaller $(1.6 \mathrm{~g})$ and marginally non-significant in 2014 (Table 3d, Fig. 4d; Appendix S1: Table S3). Fledgling mass in later broods, compared to earlier ones, was significantly higher in 2013, but significantly lower in 2014 and 2015 , whereas the effect of laying date was non-significant in 2016 (Table 3d).

The habitat $\times$ laying date interaction was non-significant in all but one of the above models: in 2014, the body mass of fledglings decreased more steeply over the season in urban sites than in forests $\left(F_{1,100}=8.98, P=0.003\right)$.

The proportion of broods that experienced starvationrelated nestling mortality was significantly higher in urban than forest habitats $\left(\chi_{1}^{2}=71.381, P<0.001\right.$; for the four years separately see Appendix S1: Table S7).

\section{DisCUSSION}

Globally, urbanization is one of the most rapidly increasing causes of habitat loss (Seto et al. 2012) and is a leading cause of species' population declines and increased extinction risk (Mcdonald et al. 2008). These impacts are often the result of large-scale alterations in habitat types, but more subtle effects can also arise through urban development altering biotic interactions including those between plants, phytophagous consumers, and their predators (Kozlov et al. 2017). Numerous environmental factors associated with towns and cities, including urban heat island effects that can be similar to those of climate change (McCarthy et al. 2010), could alter the phenology of each component of the system (Forrest 2016, Li et al. 2016) and have consequences for demography and population dynamics. In this study, we used data from multiple sites and years to assess if urbanization alters (1) the phenology of a tri-trophic plant-caterpillar-insectivorous-bird system, (2) caterpillar abundance, and (3) has resultant impacts on avian reproductive success.

Despite a consistent tendency for urban trees to leaf earlier than forest trees, site-level and individual tree-level peak dates of caterpillar biomass did not show a consistent difference between habitat types. Nevertheless, we found strong differences in the seasonality of caterpillar biomass between urban and forest sites. The dates of peak caterpillar biomass for individual trees were spread over a much longer period in cities than in forests, and while forest sites were typically characterized by a single large peak in caterpillar biomass, urban sites had several much smaller peaks throughout the season. These divergent seasonal dynamics contributed to the substantially lower caterpillar biomass in urban sites than forests. The food limitation hypothesis (Chamberlain et al. 2009, Bailly et al. 2016) predicts that this reduced availability of invertebrate prey items will adversely influence breeding success in insectivorous birds. Indeed, we found that Great Tits in urban environments, despite breeding earlier than their forest-dwelling conspecifics laid smaller 
TABLE 2. Differences in caterpillar biomass $(\mathrm{mg} / \mathrm{h})$ between urban and forest habitats

\begin{tabular}{|c|c|c|c|c|c|c|c|c|c|c|c|c|}
\hline \multirow{2}{*}{$\begin{array}{l}\text { Model } \\
\text { parameters }\end{array}$} & \multicolumn{3}{|c|}{2013} & \multicolumn{3}{|c|}{2014} & \multicolumn{3}{|c|}{2015} & \multicolumn{3}{|c|}{2016} \\
\hline & $b \pm \mathrm{SE}$ & $t$ & $P$ & $b \pm \mathrm{SE}$ & $t$ & $P$ & $b \pm \mathrm{SE}$ & $t$ & $P$ & $b \pm \mathrm{SE}$ & $t$ & $P$ \\
\hline \multicolumn{13}{|c|}{ a) Biomass over the whole sampling period $\dagger$} \\
\hline $\begin{array}{l}\text { Intercept } \\
\text { (urban mean) }\end{array}$ & $0.17 \pm 0.06$ & 3.10 & 0.002 & $0.28 \pm 0.06$ & 4.57 & $<0.001$ & $0.24 \pm 0.14$ & 1.74 & 0.081 & $-0.15 \pm 0.05$ & -3.05 & 0.002 \\
\hline Habitat & $1.10 \pm 0.09$ & 11.35 & 0.008 & $0.42 \pm 0.10$ & 4.33 & 0.049 & $0.98 \pm 0.20$ & 4.69 & 0.042 & $1.05 \pm 0.08$ & 13.56 & 0.005 \\
\hline \multicolumn{13}{|c|}{ b) Biomass over the brood-rearing period $\$$} \\
\hline $\begin{array}{l}\text { Intercept } \\
\text { (urban mean) }\end{array}$ & $0.44 \pm 0.07$ & 6.52 & $<0.001$ & $0.44 \pm 0.10$ & 4.23 & $<0.001$ & $0.53 \pm 0.23$ & 2.35 & 0.019 & $0.07 \pm 0.10$ & 0.68 & 0.498 \\
\hline Habitat & $1.02 \pm 0.12$ & 8.63 & 0.013 & $0.93 \pm 0.17$ & 5.66 & 0.029 & $1.04 \pm 0.33$ & 3.18 & 0.086 & $1.38 \pm 0.16$ & 8.86 & 0.013 \\
\hline \multicolumn{13}{|c|}{ c) Maximum biomass of individual trees $\S$} \\
\hline $\begin{array}{l}\text { Intercept } \\
\text { (urban mean) }\end{array}$ & $1.20 \pm 0.10$ & 12.20 & $<0.001$ & $1.00 \pm 0.10$ & 9.56 & $<0.001$ & $1.06 \pm 0.17$ & 6.13 & $<0.001$ & $0.65 \pm 0.11$ & 6.13 & $<0.001$ \\
\hline Habitat & $0.88 \pm 0.17$ & 5.22 & 0.035 & $0.90 \pm 0.16$ & 5.46 & 0.032 & $1.14 \pm 0.27$ & 4.16 & 0.053 & $1.27 \pm 0.17$ & 7.63 & 0.017 \\
\hline
\end{tabular}

Notes: Biomass was measured as $\mathrm{mg} / \mathrm{h}$; values were log-transformed. The "habitat" parameter shows the forest-urban biomass difference on a $\log _{10}$ scale, so positive estimates mean higher values in forest sites and a parameter estimate of 1.0 corresponds to a 10 -fold difference. Results are from linear mixed models. Statistically significant $(P<0.05)$ habitat differences are highlighted in boldface type and marginally non-significant habitat effects $(0.05<P<0.10)$ are shown in italic type.

$\dagger$ Number of frass samples, total/urban/forest: 2013: 1,084/750/334; 2014: 1,271/776/495; 2015: 1,246/876/370; 2016: 1,204/794/410.

$\$$ Number of frass samples, total/urban/forest: 2013 : 546/375/171; 2014: 527/366/161; 2015: 624/410/214; 2016: 469/325/144.

$\S$ Number of frass samples, total/urban/forest: 2013: 57/36/21; 2014: 60/36/24; 2015: 60/36/24; 2016: 60/36/24

clutches, fledged fewer offspring, produced fledglings with lower body mass, and had a greater frequency of starvationrelated nestling mortality.

The significantly higher caterpillar biomass we found in forests vs. cities provides a robust demonstration of reduced availability of an important food source for urban birds during the nesting season. Our results are based on extensive sampling of two sites per habitat type over the whole breeding period and were consistent across four study years and three measurements of caterpillar availability (whole sampling period, brood-rearing period, and maximal biomass per tree). The effect of urbanization on caterpillar availability was marked, for example during the brood-rearing period (which is probably the most sensitive period of Great Tits' reproduction to food availability) caterpillar biomass was 8.5 to 24 times higher in forests compared to urban sites. These effect sizes are greater than those previously reported by other studies with less intensive sampling (Isaksson and Andersson 2007, Marciniak et al. 2007, Glądalski et al. 2015). We have evidence, albeit temporally limited, that the reduced caterpillar abundance in urban environments strongly influences Great Tit nestling diet, with caterpillars comprising $93 \%$ of food items delivered to Great Tit nestlings at one of our forest sites but just $58 \%$ at one of our urban sites (Appendix S1: Fig. S6, Sinkovics 2014). We did not measure chick provisioning rates or total biomass of food delivered to nests, so it is possible that adults attempt to compensate for reduced availability of caterpillars by providing alternative prey items. While further studies that assess this would be useful, we found that urban nestlings were smaller and suffered from increased rates of starvationinduced mortality unrelated to predation, nest desertion, extreme weather, ectoparasites, or disease. The majority of the mortality events were partial brood losses, for which the role of starvation is also corroborated by two lines of additional evidence: first, nestlings' body mass was reduced in broods that experienced mortality not attributable to other causes of death, and second, nestlings that appeared to have died from starvation shortly after ringing already had decreased body mass at ringing. These results strongly suggest that any compensation to mitigate the adverse effects of reduced caterpillar abundance in cities is unable to prevent higher rates of starvation-induced mortality in urban areas. This could be because alternative non-caterpillar prey items may also occur at lower abundances in urban areas (Marciniak et al. 2007) or because alternative prey items provide less protein or important nutrients (such as carotenoids, essential fatty acids, or vitamin E) than the preferred caterpillar prey (Graveland and Van Gijzen 1989, Eeva et al. 2010, Razeng and Watson 2015).

Other studies have hypothesized that urban and nonurban birds experience differences in food availability because of an earlier seasonal peak in caterpillar abundance in urban environments that, due to other constraints on timing of breeding, urban birds cannot exploit (Deviche and Davies 2013, Vaugoyeau et al. 2016). We found no evidence to support this hypothesis, as dates of peak caterpillar abundance were not earlier at urban sites in our study, similarly to the finding of Wawrzyniak et al. (2015), and there were substantial differences in peak caterpillar abundance between urban and forest sites. Our findings thus strongly indicate that reduced prey availability for urban insectivorous birds is driven primarily by a generally lower abundance of caterpillars rather than changes in invertebrate phenology induced by urbanization.

Urban environments may provide less favorable feeding conditions for phytophagous insects due to the higher occurrence of nonnative tree species that provide low quality food sources for arthropods and usually support fewer lepidopteran species than native plants (Clem and Held 2015, New 2015). In our study system, however, the urban tree assemblage is dominated by native species, and a common tree at one of our forest sites, beech is widely considered to have a limited ability to support phytophagous insects (Csóka 2004). Forest trees also usually had larger caterpillar biomass than urban trees, regardless of species. Therefore, 

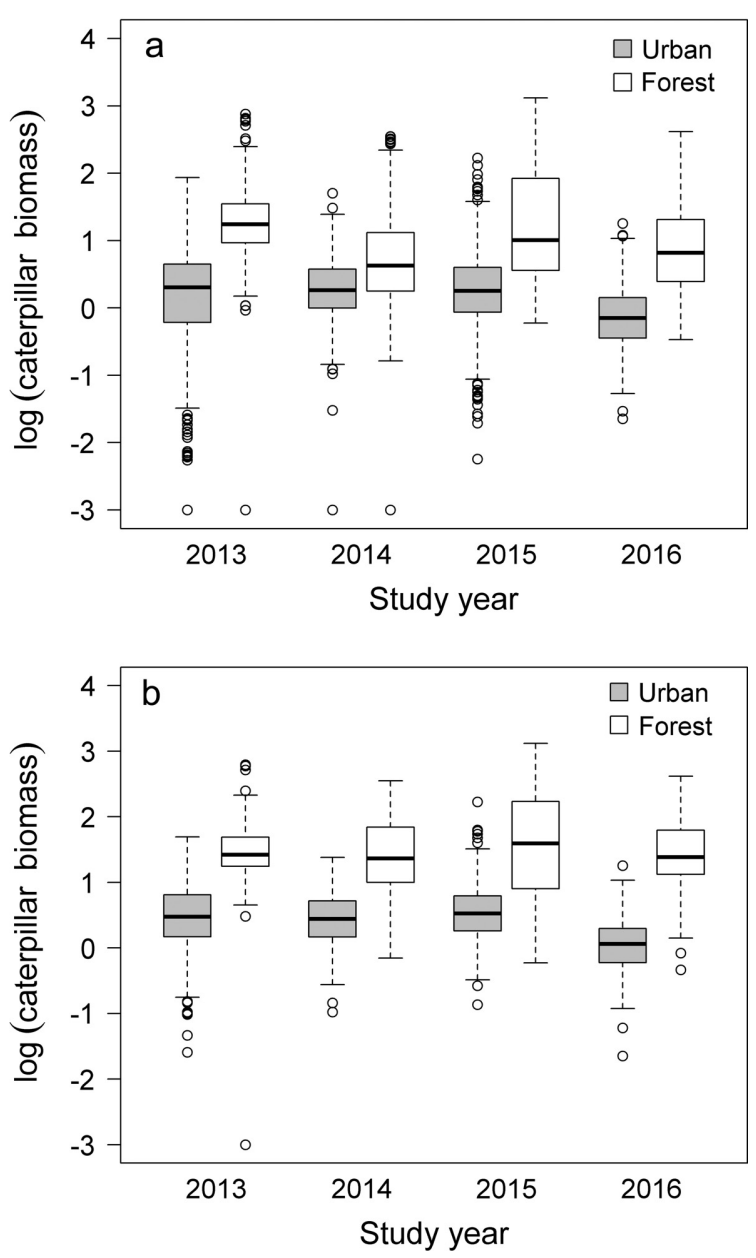

FIG. 3. Differences in caterpillar biomass (mg/h) during (a) the whole sampling period and (b) during the brood-rearing period between urban (gray) and forest (white) habitats, in the four years. Medians and interquartile ranges are respectively indicated by the thick middle lines and the boxes (see Table 2 for the results of statistical analysis), while the whiskers represent maximum and minimum values and the open circles refer to the outliers.

while we cannot rule out the possibility that some of our focal urban tree species provide low quality resources for caterpillars, it seems unlikely that this is a major cause of reduced lepidopteran abundance in urban sites and suggests that other factors are probably driving this pattern (see Management implications).

While peak caterpillar availability was not earlier in urban environments than forests, we still found strong evidence that urbanization influences seasonal patterns in caterpillar biomass. The single strong peak in caterpillar abundance that we found in forests is well documented (Zandt 1994, Verboven et al. 2001, Marciniak et al. 2007). Studies on urban caterpillar phenology are rare, and while Marciniak et al. (2007) provide some evidence for the lack of a marked, single peak in caterpillar abundance in an urban parkland, this was not confirmed by statistical analysis. Our result that urban sites have multiple smaller caterpillar peaks over the season is thus a novel finding, and this pattern was consistent across the two urban sites and four years in our study. The occurrence of multiple urban peaks that reduce synchrony in the timing of peak caterpillar biomass is further supported by our finding that urban trees had significantly greater variance in their individual peak dates of caterpillar biomass than forest trees. One potential explanation for the different seasonal patterns is that the optimal plant food for caterpillars, i.e., young leaves, might be available for a longer period in urban compared to forest habitats, perhaps because of the greater diversity of urban tree species with each species leafing at different time periods. However, our data do not support this as variance in the time of leaf emergence was similar in the two habitats and a single caterpillar peak is observed at forest sites despite sampling more than one tree species at each site. A second potential explanation for the multiple peaks in urban caterpillar biomass is that these arise from a more diverse lepidopteran community, with different species peaking in abundance at distinctive times. This seems unlikely as urban moth communities are typically less diverse than rural ones, although it is plausible that the urban moth assemblage is dominated by generalist species that have multiple generations per year (Lizee et al. 2015, New 2015). Third, the urban heat island effect that promotes a longer and warmer growing season can also enable insect populations to increase the number of generations completed within a year (Forrest 2016). Finally, greater environmental heterogeneity (e.g., in artificial lighting) and the urban heat island effect can also disrupt diapause development (Bale and Hayward 2010) leading to reduced synchrony within a population in the timing at which individuals emerge in spring (Forrest 2016). All these mechanisms may contribute to the pattern of multiple peaks in urban caterpillar biomass.

Our study demonstrated earlier laying (by between two and seven days) in urban Great Tits compared to their forest conspecifics. Our data suggest that urban Great Tit populations do not shift timing of breeding in order to exploit an earlier mass availability of caterpillars. Instead, it thus seems highly likely that the mechanisms driving earlier breeding in urban bird populations are related to the influence of urban development on the environmental cues used by birds to time their onset of reproduction, such as temperature (influenced by the urban heat island effect), day length (influenced by urban light pollution), or anthropogenic food supplies (influenced by increased supplementary feeding in urban areas). It is notable that the difference in laying date of urban and forest populations was only two days in 2014, the year with an unusually warm spring, contrasting with six to seven days in other years. These results suggest that the urban heat island effect may be a primary driver of phenological divergence between urban and rural bird populations, as such annual variation in the differences between these populations would not be expected if earlier breeding was driven mainly by other factors such as urban light pollution or anthropogenic food supplies.

Urban Great Tits had a significantly greater risk of starvation-related nestling mortality, that made an additional contribution to the smaller number of fledglings produced per successful pair beyond the effects of smaller clutch sizes. Chicks that fledged from urban nests also did so at a lower body mass compared to chicks from nests in forests. These patterns largely concur with other recent studies on urban populations of Tits and other birds (Chamberlain et al. 


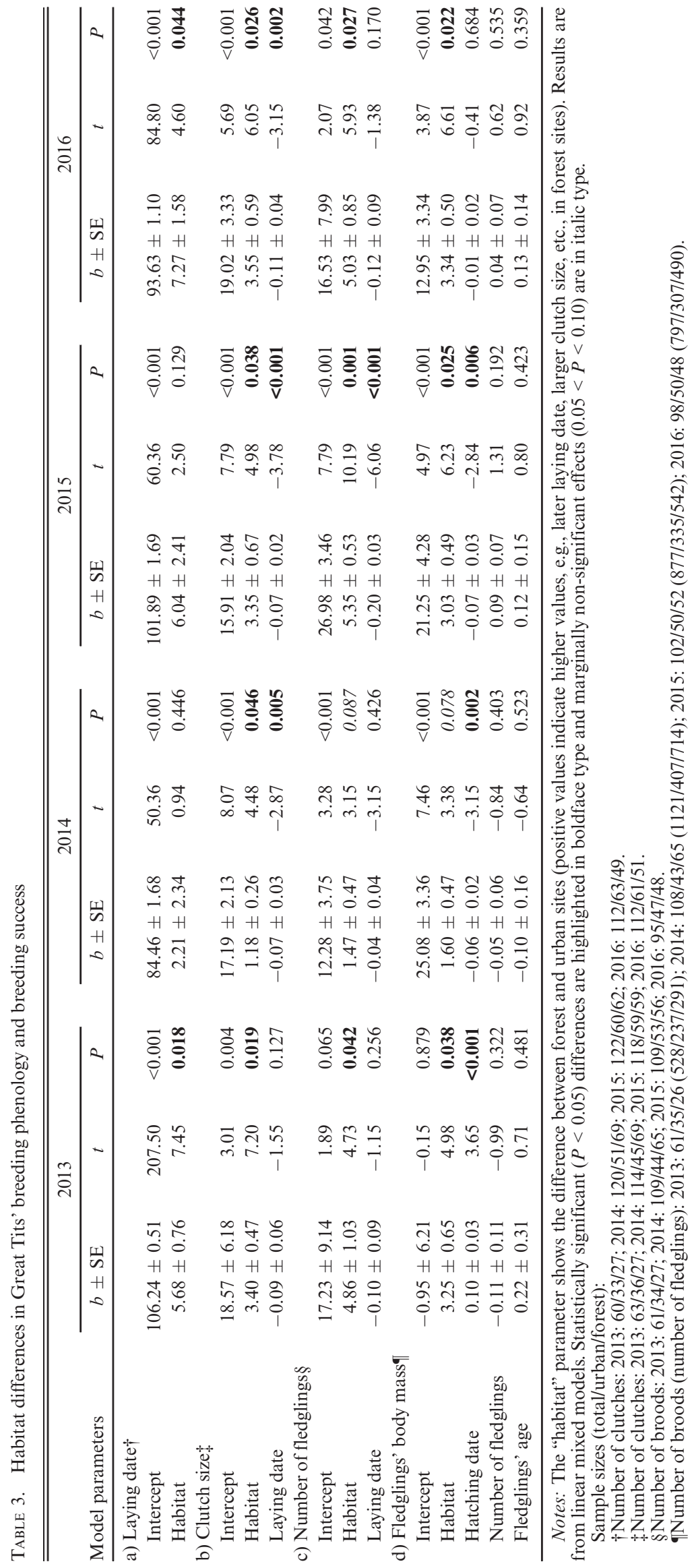



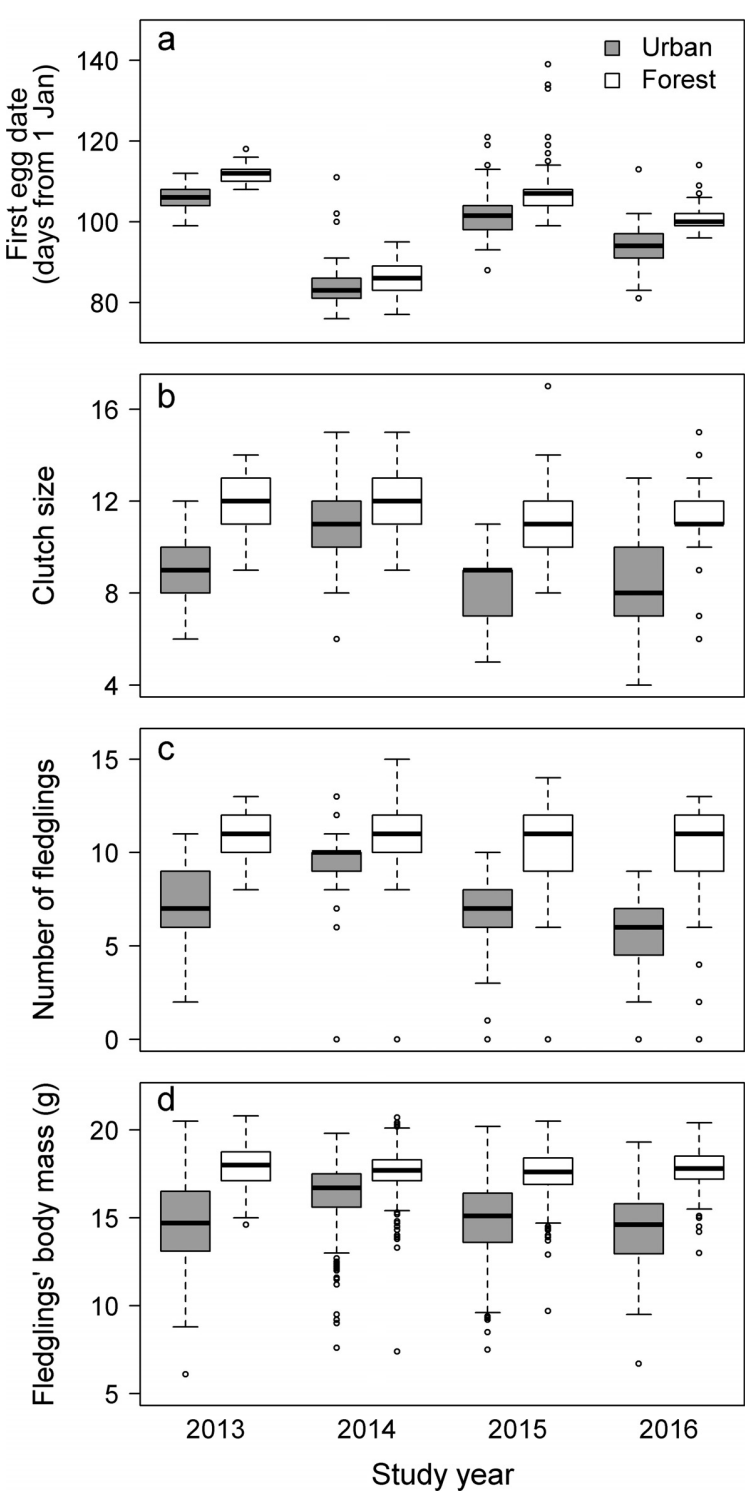

FIG. 4. Differences in breeding phenology and breeding success of urban (gray) and forest (white) Great Tits in 2013-2016: (a) laying date of the first egg per clutch, (b) clutch size, (c) number of fledglings, and (d) body mass of fledglings ( $\mathrm{c}$ and $\mathrm{d}$ were measured at $14-16 \mathrm{~d}$ of chick age). Medians and interquartile ranges are respectively indicated by the thick middle lines and boxes, while the whiskers represent maximum and minimum values and the open circles refer to the outliers.

2009, Wawrzyniak et al. 2015, Bailly et al. 2016), although differences in starvation-related chick mortality between urban and rural populations have rarely been documented. Notably, our results repeatedly document all these patterns in multiple years and multiple populations. Moreover, we simultaneously document substantially reduced abundance of caterpillars in urban environments (between 8.5 and 24 times lower than forest environments) during the Great Tit brood rearing period and reduced incorporation of caterpillars into nestling diets (from 93\% to 58\%; Appendix S1: Fig. S6).

The smaller clutches in urban areas may be advantageous because large clutches may be counter-selected in environments with low availability of nestling food and high incidence of nestling mortality due to starving. It is unclear, however, if smaller clutches in urban areas arise primarily from directional selection or from phenotypic plasticity with clutch size being reduced in lower quality environments. Despite the smaller clutch sizes of urban pairs, they still experience more frequent brood reduction during chick rearing related to starvation, suggesting that additional benefits may arise from further reductions in clutch size, although a bet-hedging strategy may allow urban birds to take advantage of occasional small increases in caterpillar availability. In addition, due in part to the reduced availability of caterpillars, urban females may be constrained from laying large clutches because of their limited access to nutrients like protein and calcium prior to laying (Seress and Liker 2015). Further studies are needed to better understand the effects of urbanization on parent birds' condition and its role in their decreased productivity.

The reduced fecundity and higher nestling mortality of urban Great Tits has implications for population size and viability in this species and presumably also in other birds suffering from similar negative effects of urbanization. We found no evidence that urban populations have a higher proportion of fledglings produced from second broods, which could compensate for the lower success of first broods, suggesting that urban populations are prone to decrease unless increased post-fledging survival negates the effect of reduced productivity. Therefore, our findings are compatible with, although do not provide explicit support for, the hypothesis that urban populations are sinks. Establishing this will require additional information on recruitment rates and adult survival of urban-breeding and forest-dwelling Great Tits (Horak and Lebreton 1998). While, in several species, adult survival is higher in urban than rural populations (Sepp et al. 2017), other species show the opposite or no effect of urbanization (Evans et al. 2015, Marzluff et al. 2016).

\section{Management implications}

Our findings imply that urbanization will reduce the reproductive success of bird species for which caterpillars are key components of the nestling diet. Such bird species often occur at lower densities in towns and cities than in more natural habitats (Lim and Sodhi 2004, Chace and Walsh 2006, Kark et al. 2007, Chen and Wang 2017; but see Evans et al. 2011) suggesting that insufficient natural food supply during the breeding season may be one factor regulating urban population sizes of these species. It is thus important to devise urban planning and management strategies to improve foraging conditions for those urban bird species whose nestlings rely on caterpillars or, more generally, on phytophagous insects. Our results indicate that food limitation occurs during the birds' breeding season, and while bird feeding is an increasingly popular practice in our region, it is less common than in Western Europe and typically limited to winter. While the evidence that typically provided supplementary foods for garden birds benefits avian population size and breeding success is equivocal (Robb et al. 2008, Plummer et al. 2013, Bonnington et al. 2014), providing invertebrates or other protein-rich bird foods during the breeding season may enhance reproductive success 
(Peach et al. 2014). Nevertheless, from an ecosystem perspective, we believe that management activities that aim to increase the abundance of phytophagous insects in the birds' environment, rather than providing supplementary food during the breeding season, will be more effective. This may also help to address long-term insect population declines (Raupp et al. 2010, Hallmann et al. 2017).

Achieving this requires addressing the numerous biotic and abiotic factors associated with towns and cities that reduce population size in lepidopterans and other insects. Urban areas (our study sites included) mainly comprise managed vegetation, which is subject to activities such as pesticide use, removal of leaf litter, mowing of grasslands, and thinning of the undergrowth. All of these activities can reduce arthropod abundance directly or indirectly (Jones and Leather 2012), for example by reducing the availability of suitable locations to pupate (Zandt 1994). Thus reductions in these vegetation management practices, or the establishment of unmanaged patches in urban parks and private gardens, would likely contribute to the maintenance of a more abundant and diverse arthropod fauna in cities. Increasing the quantity and quality of urban green spaces to improve the feeding conditions of phytophagous arthropods is also important. This is partly a function of the volume of tree canopy, with mature large trees contributing disproportionately to canopy volume and older trees are also associated with a higher insect density (Jeffries et al. 2006), which is also reflected by our results, as trees with larger canopies harbored more caterpillars. This underlines the importance of protecting large, mature trees in urban green spaces, which can be difficult as large trees are frequently cut or removed for safety reasons, to prevent damage to urban infrastructure, or to create space for additional development (Díaz-Porras et al. 2014). Protection efforts of these remnants of earlier vegetation in cities could benefit, for example, from specific educational campaigns that emphasize ecological values in addition to the aesthetic and cultural values of large trees. Planting decisions that focus on selecting tree species that can support large and diverse populations of native arthropods would also be advantageous. Native tree species are likely to be more beneficial than nonnative species (Helden et al. 2012), but more detailed consideration of species identity is needed. For example, across the urban species that we sampled, oaks tended to support the highest caterpillar biomass (Appendix S1: Table S6 and Fig. S5), concurring with previous work suggesting that this genus maintains a very rich herbivorous insect fauna, including a high number of lepidopteran species (Brandle and Brandl 2001, Csóka 2004). Our study along with the recent study of Pollock et al. (2017) suggests, however, that arthropod abundance in cites is reduced even on native trees. This infers that arthropod populations are adversely influenced by other environmental factors associated with urbanization, such as the above-mentioned intensive vegetation management practices, and potentially also the accumulation of heavy metals and other pollutants in leaves (Pincebourde et al. 2017), light pollution (Longcore and Rich 2004), and habitat fragmentation (Williams 2011, Soga and Koike 2012). Mitigating the adverse effects of all these factors on urban arthropods, thereby enhancing habitat quality for urban birds that require large numbers of caterpillars will require numerous changes to managing urban green space that will need to be tolerated by local residents.

\section{ACKNOWLedgments}

The study was financed by a grant from the National Research, Development and Innovation Office (NKFIH) of Hungary (K112838). G. Seress was supported by an NKFIH postdoctoral grant (PD 120998) during the preparation of the manuscript. V. Bókony was supported by the János Bolyai Scholarship of the Hungarian Academy of Sciences. K. L. Evans was supported by a Leverhulme Early Career Fellowship ECF/40301 and NERC grant NE/ J015369/1. We are also thankful to the two forest managing companies (Ihartü Kft. and Verga Zrt.), and to the mayors of Balatonfüred and Veszprém for permitting our field work at the study sites. The study was licensed by the Middle Transdanubian Inspectorate for Environmental Protection, Natural Protection and Water Management (permission numbers: 31559/2011 and 24861/2014).

\section{Literature Cited}

Altermatt, F. 2012. Temperature-related shifts in butterfly phenology depend on the habitat. Global Change Biology 18:2429-2438.

Bailly, J., R. Scheifler, S. Berthe, V.-A. Clément-Demange, M. Leblond, B. Pasteur, and B. Faivre. 2016. From eggs to fledging: negative impact of urban habitat on reproduction in two tit species. Journal of Ornithology 157:377-392.

Bale, J. S., and S. A. L. Hayward. 2010. Insect overwintering in a changing climate. Journal of Experimental Biology 213:980-994.

Bonnington, C., K. J. Gaston, and K. L. Evans. 2014. Relative roles of grey squirrels, supplementary feeding, and habitat in shaping urban bird assemblages. PLoS ONE 9:e109397.

Borhidi, A. 2003. Magyarország növénytársulásai. Akadémiai Kiadó, Budapest, Hungary.

Brandle, M., and R. Brandl. 2001. Species richness of insects and mites on trees: expanding Southwood. Journal of Animal Ecology 70:491-504

Chace, J. F., and J. J. Walsh. 2006. Urban effects on native avifauna: a review. Landscape and Urban Planning 74:46-69.

Chamberlain, D. E., A. R. Cannon, M. P. Toms, D. I. Leech, B. J. Hatchwell, and K. J. Gaston. 2009. Avian productivity in urban landscapes: a review and meta-analysis. Ibis 151:1-18.

Chen, S., and S. Wang. 2017. Bird diversities and their responses to urbanization in China. Pages 55-74 in E. Murgui and M. Hedblom, editors. Ecology and conservation of birds in urban environments, First edition. Springer International Publishing, Cham, Switzerland.

Clem, S. S., and D. W. Held. 2015. Species richness of eruciform larvae associated with native and alien plants in the southeastern United States. Journal of Insect Conservation 19:987-997.

Csóka, G. 2004. Herbivore insect guild of oaks in Hungary. Pages 18-27 in G. Csóka, A. Hirka, and A. Koltay, editors. Biotic damage in forests. Proceedings of the IUFRO (WP 7.03.10) Symposium. Hungarian Forest Research Institute Agroinform Publishing House, Mátrafüred, Hungary.

Deviche, P., and S. Davies. 2013. Reproductive phenology of urban birds: environmental cues and mechanisms. Pages 98-115 in D. Gil and H. Brumm, editors. Avian urban ecology: behavioural and physiological adaptations, First edition. Oxford University Press, Oxford, UK.

Diamond, S. E., H. Cayton, T. Wepprich, C. N. Jenkins, R. R. Dunn, N. M. Haddad, and L. Ries. 2014. Unexpected phenological responses of butterflies to the interaction of urbanization and geographic temperature. Ecology 95:2613-2621.

Díaz-Porras, D. F., K. J. Gaston, and K. L. Evans. 2014. 110 Years of change in urban tree stocks and associated carbon storage. Ecology and Evolution 4:1413-1422.

Dunn, C. P., and L. Heneghan. 2011. Composition and diversity of urban vegetation. Pages 103-114 in J. H. Breuste, T. Elmqvist, G. 
Guntenspergen, P. James, and N. E. McIntyre, editors. Urban ecology: patterns, processes, and applications. First edition. Oxford University Press, Oxford, UK.

Eeva, T., S. Helle, J. P. Salminen, and H. Hakkarainen. 2010. Carotenoid composition of invertebrates consumed by two insectivorous bird species. Journal of Chemical Ecology 36:608-613.

Evans, K. L., D. E. Chamberlain, B. J. Hatchwell, R. D. Gregory, and K. J. Gaston. 2011. What makes an urban bird? Global Change Biology 17:32-44.

Evans, B. S., T. B. Ryder, R. Reitsma, A. H. Hurlbert, and P. P. Marra. 2015. Characterizing avian survival along a rural-tourban land use gradient. Ecology 96:1631-1640.

Forrest, J. R. 2016. Complex responses of insect phenology to climate change. Current Opinion in Insect Science 17:49-54.

Gil, D., and H. Brumm. 2014. Avian urban ecology behavioural and physiological adaptations, First edition. Oxford University Press, Oxford, UK.

Glądalski, M., M. Bańbura, A. Kaliński, M. Markowski, J. Skwarska, J. Wawrzyniak, P. Zieliński, I. Cyzewska, and J. Bańbura. 2015. Inter-annual and inter-habitat variation in breeding performance of Blue tits (Cyanistes caeruleus) in central Poland. Ornis Fennica 92:34-42.

Grabenweger, G., P. Kehrli, B. Schlick-Steiner, F. Steiner, M. Stolz, and S. Bacher. 2005. Predator complex of the horse chestnut leafminer Cameraria ohridella: Identification and impact assessment. Journal of Applied Entomology 129:353-362.

Graveland, J., and T. Van Gijzen. 1989. Arthropods and seeds are not sufficient as calcium sources for shell formation and skeletal growth in passerines. Ardea 82:299-314.

Hallmann, C. A., et al. 2017. More than 75 percent decline over 27 years in total flying insect biomass in protected areas. PLoS ONE 12:e0185809.

Hegyi, G., G. Nagy, and J. Török. 2013. Reduced compensatory growth capacity in mistimed broods of a migratory passerine. Oecologia 172:279-291.

Helden, A. J., G. C. Stamp, and S. R. Leather. 2012. Urban biodiversity: Comparison of insect assemblages on native and nonnative trees. Urban Ecosystems 15:611-624.

Horak, P., and J.-D. Lebreton. 1998. Survival of adult Great Tits Parus major in relation to sex and habitat; a comparison of urban and rural populations. Ibis 140:205-209.

Isaksson, C., and S. Andersson. 2007. Carotenoid diet and nestling provisioning in urban and rural Great tits Parus major. Journal of Avian Biology 38:564-572.

Jeffries, J. M., R. J. Marquis, and R. E. Forkner. 2006. Forest age influences oak insect herbivore community structure, richness, and density. Ecological Applications 16:901-912.

Jones, E. L., and S. R. Leather. 2012. Invertebrates in urban areas: a review. European Journal of Entomology 109:463-478.

Kark, S., A. Iwaniuk, A. Schalimtzek, and E. Banker. 2007. Living in the city: Can anyone become an "urban exploiter"? Journal of Biogeography 34:638-651.

Kettel, E. F., L. K. Gentle, J. L. Quinn, and R. W. Yarnell. 2018. The breeding performance of raptors in urban landscapes: a review and meta-analysis. Journal of Ornithology 159:1-18.

Kozlov, M. V., V. Lanta, V. Zverev, K. Rainio, M. A. Kunavin, and E. L. Zvereva. 2017. Decreased losses of woody plant foliage to insects in large urban areas are explained by bird predation. Global Change Biology 23:4354 4364.

Leong, M., L. C. Ponisio, C. Kremen, R. W. Thorp, and G. K. Roderick. 2016. Temporal dynamics influenced by global change: Bee community phenology in urban, agricultural, and natural landscapes. Global Change Biology 22:1046-1053.

Li, X., Y. Zhou, R. G. Asrar, J. Mao, X. Li, and W. Li. 2016. Response of vegetation phenology to urbanization in the conterminous United States. Global Change Biology 23:28182830.

Lim, H. C., and N. S. Sodhi. 2004. Responses of avian guilds to urbanisation in a tropical city. Landscape and Urban Planning 66:199-215.
Lizee, M.-H., T. Tatoni, and M. Deschamps-Cottin. 2015. Nested patterns in urban butterfly species assemblages: respective roles of plot management, park layout and landscape features. Urban Ecosystems 19:205-224.

Longcore, T., and C. Rich. 2004. Ecological light pollution. Frontiers in Ecology and the Environment 2:191-198.

Marciniak, B., J. Nadolski, M. Nowakowska, B. Loga, and J. Bańbura. 2007. Habitat and annual variation in arthropod abundance affects Blue tit Cyanistes caeruleus reproduction. Acta Ornithologica 42:53-62.

Martin, T. E. 1995. Avian life history evolution in relation to nest sites, nest predation, and food. Ecological Monographs 65:101-127.

Marzluff, J. M., B. Clucas, M. D. Oleyar, and J. DeLap. 2016. The causal response of avian communities to suburban development: a quasi-experimental, longitudinal study. Urban Ecosystems 19:1597-1621.

McCarthy, M. P., M. J. Best, and R. A. Betts. 2010. Climate change in cities due to global warming and urban effects. Geophysical Research Letters 37:L09705.

Mcdonald, R. I., P. Kareiva, and R. T. T. Forman. 2008. The implications of current and future urbanization for global protected areas and biodiversity conservation. Biological Conservation 141:1695-1703.

McIntyre, N. E. 2000. Ecology of urban arthropods: a review and a call to action. Annals of the Entomological Society of America 93:825-835.

Neil, K., and J. Wu. 2006. Effects of urbanization on plant flowering phenology: a review. Urban Ecosystems 9:243-257.

New, T. R. 2015. Insect conservation and urban environments, First edition. Springer International Publishing, Cham, Switzerland.

Peach, W. J., D. K. Sheehan, and W. B. Kirby. 2014. Supplementary feeding of mealworms enhances reproductive success in garden nesting House Sparrows Passer domesticus. Bird Study 61:378-385.

Perrins, C. M. 1991. Tits and their caterpillar food supply. Ibis 133:49-54.

Pincebourde, S., J. van Baaren, S. Rasmann, P. Rasmont, G. Rodet, B. Martinet, and P.-A. Calatayud. 2017. Plant-insect interactions in a changing world. Pages 289-332 in N. Sauvion, D. Thiéry and P.-A. Calatayud, editors. Advances in botanical research. Volume 81 , Insect-plant interactions in a crop protection perspective. First edition. Elsevier, Amsterdam, The Netherlands.

Plummer, K. E., S. Bearhop, D. I. Leech, D. E. Chamberlain, and J. D. Blount. 2013. Winter food provisioning reduces future breeding performance in a wild bird. Scientific Reports 3:2002.

Pollock, C. J., P. Capilla-Lasheras, R. A. R. McGill, B. Helm, and D. M. Dominoni. 2017. Integrated behavioural and stable isotope data reveal altered diet linked to low breeding success in urbandwelling blue tits (Cyanistes caeruleus). Scientific Reports 7:5014.

R Core Team. 2016. R: a language and environment for statistical computing. R Foundation for Statistical Computing, Vienna, Austria. www.r-project.org

Raupp, M. J., P. M. Shrewsbury, and D. A. Herms. 2010. Ecology of herbivorous arthropods in urban landscapes. Annual Review of Entomology 55:19-38.

Razeng, E., and D. M. Watson. 2015. Nutritional composition of the preferred prey of insectivorous birds: popularity reflects quality. Journal of Avian Biology 46:89-96.

Robb, G. N., R. A. McDonald, D. E. Chamberlain, and S. Bearhop. 2008. Food for thought: supplementary feeding as a driver of ecological change in avian populations. Frontiers in Ecology and the Environment 6:476-484.

Rolinski, S., H. Horn, T. Petzoldt, and L. Paul. 2007. Identifying cardinal dates in phytoplankton time series to enable the analysis of long-term trends. Oecologia 153:997-1008.

Rolinski, S., S. Sachse and T. Petzoldt. 2015. Package "cardidates" identification of cardinal dates in ecological time series. https:// CRAN.R-project.org/package $=$ cardidates

Sepp, T., K. J. McGraw, A. Kaasik, and M. Giraudeau. 2017. A review of urban impacts on avian life-history evolution: Does city living lead to slower pace of life? Global Change Biology 24:1-18. 
Seress, G., and A. Liker. 2015. Habitat urbanization and its effects on birds. Acta Zoologica Academiae Scientiarum Hungaricae 61:373-408.

Seress, G., V. Bókony, I. Pipoly, T. Szép, K. Nagy, and A. Liker. 2012. Urbanization, nestling growth and reproductive success in a moderately declining house sparrow population. Journal of Avian Biology 43:403-414.

Seress, G., E. Vincze, I. Pipoly, T. Hammer, S. Papp, B. Preiszner, V. Bókony, and A. Liker. 2017. Effects of capture and video-recording on the behavior and breeding success of Great Tits in urban and forest habitats. Journal of Field Ornithology 88:299-312.

Seto, K. C., B. Güneralp, and L. R. Hutyra. 2012. Global forecasts of urban expansion to 2030 and direct impacts on biodiversity and carbon pools. Proceedings of the National Academy of Sciences USA 109:16083-16088.

Shawkey, M. D., R. Bowman, and G. E. Woolfenden. 2004. Why is brood reduction in Florida scrub-jays higher in suburban than in wildland habitats? Canadian Journal of Zoology 82:1427-1435.

Sinkovics, C. 2014. A fiókatáplálék mennyisége, minősége és szezonalitása városi és erdei széncinege (Parus major) populációkban. Institute for Biology, Szent István University, Budapest, Hungary.

Soga, M., and S. Koike. 2012. Relative importance of quantity, quality and isolation of patches for butterfly diversity in fragmented urban forests. Ecological Research 27:265-271.

Solonen, T. 2001. Breeding of the Great tit and Blue tit in urban and rural habitats in southern Finland. Ornis Fennica 78:49-60.

Tinbergen, J. M., and M. W. Dietz. 1994. Parental energy expenditure during brood rearing in the Great tit (Parus major) in relation to body mass, temperature, food availability and clutch size. Functional Ecology 8:563-572.

Tomasevic, J. A., and J. M. Marzluff. 2017. Cavity nesting birds along an urban-wildland gradient: is human facilitation structuring the bird community? Urban Ecosystems 20:435-448.

Troxel, B., M. Piana, M. S. Ashton, and C. Murphy-Dunning. 2013. Relationships between bole and crown size for young urban trees in the northeastern USA. Urban Forestry \& Urban Greening 12:144-153.
Van Noordwijk, A. J., R. H. McCleery, and C. M. Perrins. 1995. Selection for the timing of great tit breeding in relation to caterpillar growth and temperature. Journal of Animal Ecology 64:451.

Vaugoyeau, M., et al. 2016. Interspecific variation in the relationship between clutch size, laying date and intensity of urbanization in four species of hole-nesting birds. Ecology and Evolution 6:5907-5920.

Verboven, N., J. M. Tinbergen, and S. Verhulst. 2001. Food, reproductive success and multiple breeding in the Great tit Parus major. Ardea 89:387-406.

Vincze, E., G. Seress, M. Lagisz, S. Nakagawa, N. J. Dingemanse, and P. Sprau. 2017. Does urbanization affect predation of bird nests? A meta-analysis. Frontiers in Ecology and Evolution 5:112 .

Vitasse, Y. 2013. Ontogenic changes rather than difference in temperature cause understory trees to leaf out earlier. New Phytologist 198:149-155.

Wawrzyniak, J., A. Kaliński, M. Glądalski, M. Bańbura, M. Markowski, J. Skwarska, P. Zieliński, I. Cyzewska, and J. Bańbura. 2015. Long-term variation in laying date and clutch size of the Great tit Parus major in central Poland: a comparison between urban parkland and deciduous forest. Ardeola 62:311-322.

Whittingham, M. J., P. A. Stephens, R. B. Bradbury, and R. P. Freckleton. 2006. Why do we still use stepwise modelling in ecology and behaviour? Journal of Animal Ecology 75:1182-1189.

Williams, M. R. 2011. Habitat resources, remnant vegetation condition and area determine distribution patterns and abundance of butterflies and day-flying moths in a fragmented urban landscape, south-west Western Australia. Journal of Insect Conservation 15:37-54.

Zandt, H. S. 1994. A comparison of three sampling techniques to estimate the population size of caterpillars in trees. Oecologia 97:399-406.

Zuur, A. F., E. N. Ieno, N. Walker, A. A. Saveliev, and G. M. Smith. 2009. Mixed effects models and extensions in ecology with R. Springer New York, New York, New York, USA.

\section{SUPPORTING INFORMATION}

Additional supporting information may be found online at: http://onlinelibrary.wiley.com/doi/10.1002/eap.1730/full

Data Availability

Data available from the Dryad Digital Repository: https://doi.org/10.5061/dryad.5jn4j2f 